\title{
Climate bifurcation during the last deglaciation?
}

\author{
T. M. Lenton ${ }^{1}$, V. N. Livina ${ }^{2}$, V. Dakos ${ }^{3}$, and M. Scheffer ${ }^{3}$ \\ ${ }^{1}$ College of Life and Environmental Sciences, University of Exeter, Hatherly Laboratories, Prince of Wales Road, \\ Exeter EX4 4PS, UK \\ ${ }^{2}$ School of Environmental Sciences, University of East Anglia, Norwich NR4 7TJ, UK \\ ${ }^{3}$ Aquatic Ecology and Water Quality Management, Wageningen University, Wageningen, The Netherlands
}

Correspondence to: T. M. Lenton (t.m.lenton@exeter.ac.uk)

Received: 5 December 2011 - Published in Clim. Past Discuss.: 12 January 2012

Revised: 4 May 2012 - Accepted: 12 June 2012 - Published: 9 July 2012

\begin{abstract}
There were two abrupt warming events during the last deglaciation, at the start of the Bølling-Allerød and at the end of the Younger Dryas, but their underlying dynamics are unclear. Some abrupt climate changes may involve gradual forcing past a bifurcation point, in which a prevailing climate state loses its stability and the climate tips into an alternative state, providing an early warning signal in the form of slowing responses to perturbations, which may be accompanied by increasing variability. Alternatively, short-term stochastic variability in the climate system can trigger abrupt climate changes, without early warning. Previous work has found signals consistent with slowing down during the last deglaciation as a whole, and during the Younger Dryas, but with conflicting results in the run-up to the Bølling-Allerød. Based on this, we hypothesise that a bifurcation point was approached at the end of the Younger Dryas, in which the cold climate state, with weak Atlantic overturning circulation, lost its stability, and the climate tipped irreversibly into a warm interglacial state. To test the bifurcation hypothesis, we analysed two different climate proxies in three Greenland ice cores, from the Last Glacial Maximum to the end of the Younger Dryas. Prior to the Bølling warming, there was a robust increase in climate variability but no consistent slowing down signal, suggesting this abrupt change was probably triggered by a stochastic fluctuation. The transition to the warm Bølling-Allerød state was accompanied by a slowing down in climate dynamics and an increase in climate variability. We suggest that the Bølling warming excited an internal mode of variability in Atlantic meridional overturning circulation strength, causing multi-centennial climate fluctuations. However, the return to the Younger Dryas cold state increased climate stability. We find no consistent evidence
\end{abstract}

for slowing down during the Younger Dryas, or in a longer spliced record of the cold climate state before and after the Bølling-Allerød. Therefore, the end of the Younger Dryas may also have been triggered by a stochastic perturbation.

\section{Introduction}

Human civilisations have developed in the stable climate of the Holocene interglacial epoch, but now there is concern that human activities could tip the climate out of its current regime (Alley et al., 2003; Lenton et al., 2008). An important question is whether any early warning can be provided of such an approaching threshold change or "tipping point" in the climate system (Lenton, 2011). In general, for a system slowly approaching a threshold where its current state becomes unstable, and it transitions to some other state, one can expect to see it become more sluggish in its response to small perturbations (Scheffer et al., 2009). Mathematically speaking, for systems gradually approaching a codimension-1 bifurcation point in their equilibrium solutions, the real part of their leading eigenvalue tends toward zero, indicating a tendency toward infinitely slow recovery from perturbations. This phenomenon, known as "critical slowing down" in dynamical systems theory, has long been appreciated in physics (Wiesenfeld and McNamara, 1986) and ecology (Wissel, 1984), but has only recently been applied to climate dynamics, where it can be detected as increasing autocorrelations in time series data approaching abrupt transitions (Held and Kleinen, 2004; Livina and Lenton, 2007; Dakos et al., 2008; Lenton, 2011). 
Rising variance has also been suggested as an early warning signal prior to abrupt transitions (Carpenter and Brock, 2006), but there is an ongoing debate as to how robust an indicator it is (Dakos et al., 2012; Ditlevsen and Johnsen, 2010). Following the fluctuation-dissipation theorem, it has been argued that both rising variance and rising autocorrelation must be detected together to have a robust early warning signal of approaching bifurcation (Ditlevsen and Johnsen, 2010). Furthermore, the ratio of variance to correlation time should remain a constant, set by the noise intensity (assuming it is constant) (Ditlevsen and Johnsen, 2010). However, several counterexamples have been provided, where systems show rising autocorrelation prior to bifurcations, but variance does not rise, and indeed may decrease (Livina et al., 2012; Dakos et al., 2012).

Paleo-data approaching past abrupt climate changes can provide a testing ground for these proposed early warning indicators (Livina and Lenton, 2007; Dakos et al., 2008; Ditlevsen and Johnsen, 2010). Alternatively, the indicators can be used to test hypotheses that particular past abrupt climate transitions involved underlying bifurcations. That is the approach we take here.

The last deglaciation was characterised by several abrupt climate changes, notably warming at the start of the BøllingAllerød period, cooling into the Younger Dryas, and warming at the end of the Younger Dryas (into the Preboreal). The cooling at the onset of the Younger Dryas was less abrupt than the two warming events (Steffensen et al., 2008). The first identification of early warning signals in paleo-climate data was found across the entire deglacial sequence in Greenland ice core (GISP2) $\delta^{18} \mathrm{O}$ data, and tentatively associated with the Preboreal onset at the end of the Younger Dryas (Livina and Lenton, 2007) (although it could equally have been linked to the Bølling warming). Subsequent work found an early warning signal prior to the Bølling warming in the same GISP2 data, and also discovered early warning prior to the end of the Younger Dryas in marine sediment data from the tropical Atlantic (Cariaco basin) (Dakos et al., 2008).

However, analysis of higher-resolution North Greenland (NGRIP) Ice Core project data failed to find early warning signals prior to any of the abrupt Dansgaard-Oeschger (DO) events during the last ice age, including the Bølling warming (Ditlevsen and Johnsen, 2010). These events have instead been characterised as noise-induced transitions between preexisting states (or attractors) in the climate system (Ditlevsen and Johnsen, 2010; Livina et al., 2010). Whereas slow forcing past a bifurcation point should show the early warning signal of critical slowing down, rapid forcing (stochastic or otherwise) between attractors is not expected to (Ditlevsen and Johnsen, 2010; Lenton, 2011).

Based on existing results, we suggest a simple conceptual model of the glacial climate in terms of a slow-fast system (Fig. 1). This hinges on a time scale separation between a fast variable - in this case Atlantic meridional overturning circulation (AMOC, coupled to sea-ice and the atmosphere)

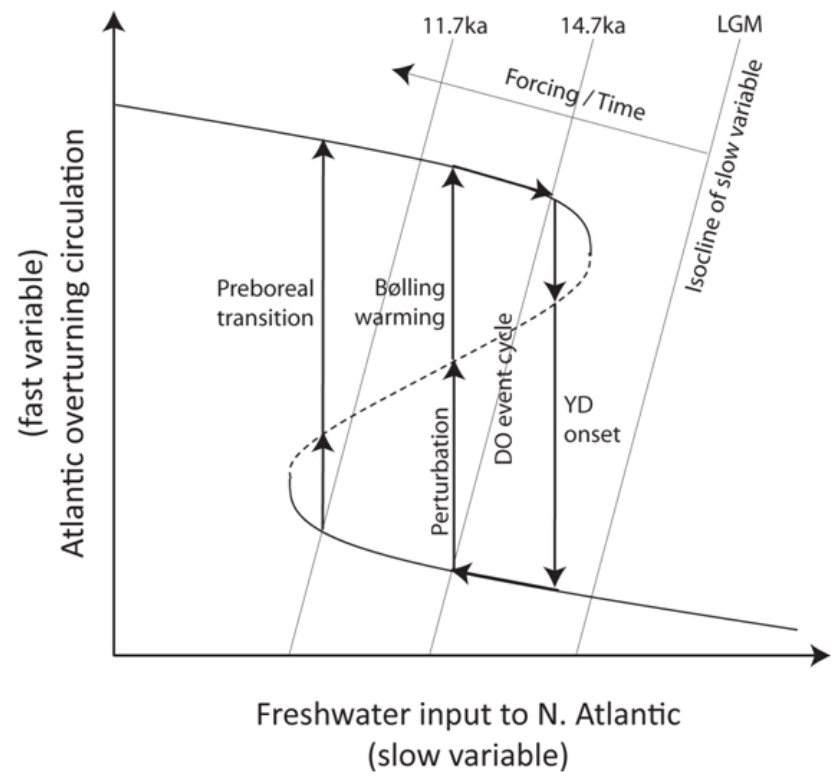

Fig. 1. Simple conceptual model of deglacial climate dynamics in terms of a slow-fast system. This incorporates the hypothesis that during the deglaciation there is a gradual approach toward a bifurcation in which the cold climate state loses its stability.

- and a slow variable - freshwater input to the North Atlantic - in turn linked to the volume of Northern Hemisphere ice sheets. For intermediate values of global ice volume (and, correspondingly, freshwater input to the North Atlantic), the AMOC is assumed to have two alternative states: strong or weak, and the climate is correspondingly warm (inter-stadial) or cold (stadial), particularly in the North Atlantic region. However, the fast variable, AMOC, is assumed to exert some influence on the slow variable, freshwater input to the North Atlantic, such that it slowly destabilises whatever state the climate is in, thus giving the system some propensity to oscillate (especially in the presence of internal, stochastic variability). Specifically, the strong AMOC, inter-stadial warm state is assumed to melt Northern Hemisphere ice sheets, increasing freshwater input to the North Atlantic, whereas the weak AMOC, stadial cold state is assumed to grow Northern Hemisphere ice sheets, decreasing freshwater input to the North Atlantic. Additionally, it is assumed that even slower factors, namely orbital forcing and associated amplifying changes in global ice volume and atmospheric $\mathrm{CO}_{2}$, which create the $\sim 100 \mathrm{kyr}$ glacial-interglacial cycles, can alter the stability regime of the AMOC by moving the isocline of the slow variable (Fig. 1) (Crucifix, 2012).

This minimal model of a slow-fast system (Fig. 1) can be applied to the overall pattern of DO events during the last ice age, but here we focus on the last deglaciation. We assume the systematic drift toward lower global ice volume, which characterises deglaciation, had its own dynamics and can be treated here as an external forcing. Initially, in the Last Glacial Maximum (LGM), only the cold stadial climate 
state is assumed to have been stable, consistent with previous work (Livina et al., 2010). The onset of deglaciation then slowly shifted the stability regime until the warm interstadial state became marginally stable. The Bølling warming is assumed to have been triggered by a fast perturbation around $14.7 \mathrm{ka}$, and involved an abrupt strengthening of the AMOC. The warmth of the Bølling-Allerød state in turn accelerated Northern Hemisphere ice sheet melt, increasing freshwater input to the North Atlantic and destabilising the strong AMOC. This ultimately contributed to a switch back into cold conditions at the start of the Younger Dryas.

The coldness of the Younger Dryas state then encouraged Northern Hemisphere ice sheets to regrow, slowing global sea-level rise (Bard et al., 2010), and tending to reduce freshwater input to the North Atlantic. Global deglaciation still proceeded and we suggest it contributed to destabilising the cold climate state (and stabilising the alternative, warm climate state). We hypothesise that an overall reduction in freshwater input to the North Atlantic during the Younger Dryas caused the AMOC to approach a bifurcation point, in which the weak (stadial) overturning state lost its stability. In support, there is evidence for abrupt strengthening of the AMOC at the end of the Younger Dryas (McManus et al., 2004). Furthermore, subsequent meltwater pulses 1B (Bard et al., 2010) and the $8.2 \mathrm{ka}$ event caused only a transient weakening of the AMOC (McManus et al., 2004) and associated cooling, rather than a sustained collapse (as might be expected if the cold climate state was still stable).

The alternative null hypothesis is that the end of the Younger Dryas was a purely noise-induced transition between alternative climate states, with no preceding trend of destabilisation and therefore no early warning. Of course, if a bifurcation was being approached, it would have made it easier for the Younger Dryas to be ended by a stochastic fluctuation, so the observed abrupt transition likely did involve internal variability. The key question then is whether it was preceded by any signs of destabilisation.

To test hypotheses for the nature of abrupt climate warming events at the start of the Bølling-Allerød and the end of the Younger Dryas, we extract potential early warning indicators from two different climate proxies in three different Greenland ice-cores: GRIP (Greenland ice core project) (Dansgaard et al., 1993), GISP2 (Greenland ice sheet project 2) (Alley, 2004), and NGRIP (North Greenland ice core project) (NGRIP, 2004). First, we establish whether a signal consistent with slowing down, which has been detected previously across the whole deglaciation (Livina and Lenton, 2007), is present in multiple Greenland ice-core records. Next, we re-examine whether or not there is a signal of slowing down prior to the Bølling warming (Dakos et al., 2008; Ditlevsen and Johnsen, 2010). Then, we examine whether slowing down detected during the Younger Dryas in the tropical Atlantic (Dakos et al., 2008) is also present in Greenland. We use two different measures of increasing correlation (across different time scales) to look for critical slow- ing down, and also monitor variance, conducting a sensitivity analysis for the statistical parameters in our methods, to assess the robustness of the detected signals. In the Discussion, we relate our findings to other paleo-data, to processbased models of abrupt deglacial climate changes (Crucifix and Berger, 2002; Weaver et al., 2000; Liu et al., 2009; Ganopolski and Rahmstorf, 2001), and to alternative models for the underlying dynamics (Timmermann et al., 2003; Colin de Verdiere, 2006; Crucifix, 2012).

\section{Methods}

\subsection{Data}

The GRIP, NGRIP and GISP2 ice cores have recently been synchronised on the Greenland Ice Core Chronology 2005 (GICC05) time scale through the last deglaciation (Rasmussen et al., 2008), and these data form the basis of our analysis. Critical slowing down, if it occurs, is a property of the slowest decay mode of a system, so we concentrate primarily on 20-yr resolution ice core records, which aggregate over shorter time scale variability and fast decay modes.

For each ice core, we examined two proxy records. We focus first on the $\delta^{18} \mathrm{O}$ water isotope record, which is a proxy for past air-temperature, but can also be influenced by changing water source temperatures and snowfall seasonality. Secondly, we examined the $\left[\mathrm{Ca}^{++}\right]$record, which represents dust from soil-derived carbonates, and thus can capture changes in climate aridity, winds or dust source regions. $\left[\mathrm{Ca}^{++}\right]$is greatest in cold, dry intervals and fluctuates over orders of magnitude, falling to very low levels in warm, wet intervals such as the Bølling-Allerød. Hence, it is common to consider $\log _{\mathrm{e}}\left(\left[\mathrm{Ca}^{++}\right]\right)$, which shows a good anti-correlation with $\delta^{18} \mathrm{O}$ and exhibits comparable fluctuations. We follow the convention of showing $-\log _{\mathrm{e}}\left[\mathrm{Ca}^{++}\right]$for ease of visual comparison with $\delta^{18} \mathrm{O}$.

We concentrate on the interval from the end of DO event $2 \sim 22.9 \mathrm{ka}$ ( $22880 \mathrm{yr}$ b2k on the GICC05 time scale), approaching the Last Glacial Maximum, to the abrupt warming at the end of the Younger Dryas $\sim 11.7 \mathrm{ka}(11740 \mathrm{yr}$ b2k). First, we analyse the whole interval ( $n=558$ points), including the abrupt transitions into and out of the Bølling-Allerød. Next, we consider just the run-up to the Bølling warming (DO event 1$) \sim 14.7 \mathrm{ka}(14740 \mathrm{yr}$ b2k) ( $n=408$ points). Then, we remove the Bølling-Allerød from the original series, splicing together the run-up to the Bølling warming (stopping $14760 \mathrm{yr}$ b2k) and the start of the Younger Dryas $\sim 12.7 \mathrm{ka}(12680 \mathrm{yr}$ b2k) to give a composite series representing just the cold, stadial climate state ( $n=455$ points). This does not introduce any significant discontinuities into any of the datasets.

The Bølling-Allerød and Younger Dryas periods are each too short $(n<100$ points each) to get reliable results with 20 -yr resolution data. Hence, we also examined annual 
resolution $\log _{\mathrm{e}}(\mathrm{Ca})$ data from GRIP, in order to get a denser time series. This dataset is on a different time scale and uses different units (but these changes are not critical to the results).

For each dataset, we extracted two different indicators of slowing down: the AR(1) coefficient (ACF-indicator), and a rescaled DFA scaling exponent (DFA-indicator), and also monitored changes in variance.

\subsection{Autocorrelation function (ACF-indicator)}

Slowing down is measured by an increase in lag-1 autocorrelation, estimated by fitting an autoregressive model of order 1 (linear AR(1)-process) of the form $y_{t+\Delta t}=c \cdot y_{t}+\sigma \eta_{t}$, using an ordinary least-squares fitting method, where $t$ is time, $\eta_{t}$ is a Gaussian white noise process of variance $\sigma^{2}$, and $c$ is the autoregressive coefficient; $c=\exp (-\kappa \Delta t)$, where $\kappa$ is the decay rate of perturbations. The decay rate of the major mode, $\kappa$, tends to zero (i.e. $c \rightarrow 1$ ) as bifurcation is approached (Held and Kleinen, 2004). The changing estimated value of the $\operatorname{AR}(1)$ coefficient, $c$, as one moves through a time series is referred to here as the "ACF indicator" - previously termed the "propagator" (Held and Kleinen, 2004).

\subsection{Detrended fluctuation analysis (DFA-indicator)}

Slowing down causes an increase in short-term memory, which is measured using detrended fluctuation analysis. DFA extracts the fluctuation function of window size, $s$, which increases as a power law if the data series is long-term powerlaw correlated; $F(s) \propto s^{\alpha}$, where $\alpha$ is the DFA scaling exponent. We consider only the short-term regime, in which as $c \rightarrow 1$ and the data approach critical behaviour, the slowing exponential decay is well approximated by a power law in which $\alpha \rightarrow 1.5$ (corresponding to a random walk). The DFA exponent is rescaled to give a "DFA indicator" that has been calibrated against the ACF indicator for direct comparison, and reaches value 1 (rescaled from 1.5) at critical behaviour (Livina and Lenton, 2007).

\subsection{Variance}

We monitor variance, calculated as standard deviation, for comparison with previous work (Ditlevsen and Johnsen, 2010). If the fluctuation-dissipation theorem is applicable, then, as a bifurcation is approached (and $\kappa \rightarrow 0$ ), variance of the system is expected to increase according to $\operatorname{Var}(y)$ $=\sigma^{2} / 2 \kappa$, where $\sigma^{2}$ is the variance of the noise (Ditlevsen and Johnsen, 2010). However, variance may not increase if, for example, critical slowing down reduces the capacity of a system to follow high frequency fluctuations, or if a system becomes less sensitive to stochastic fluctuations as it approaches a threshold (Dakos et al., 2012).

\subsection{Detrending}

Due to non-stationarities in the paleo-climate records, it is necessary to remove trends before estimating the slowing down indicators or variance. DFA includes an inherent, internal detrending routine (Livina and Lenton, 2007), which is of low-order here and equivalent to simple linear detrending. Before calculating the ACF-indicator or variance, we examined several de-trending approaches (Lenton et al., 2012) and chose Gaussian filtering, which fits a Gaussian kernel smoothing function across the whole record prior to transition (Dakos et al., 2008). Results are similar when Gaussian filtering is applied only within the sliding window (Lenton et al., 2012). The fit is subtracted from the record to obtain the residual data series. Bandwidth for the kernel determines the degree of smoothing, and should be chosen such that it neither over-fits the data nor filters out low frequencies in the record. Here, a default bandwidth of 25 is typically used, but as part of our sensitivity analysis, the bandwidth size of the Gaussian filtering is varied over 5-250 (Dakos et al., 2008).

\subsection{Sliding window length}

All our indicators are estimated within a sliding window over a time series preceding the onset of a transition. The choice of the sliding window length is a trade-off between timeresolution (data availability) and reliability of the estimate for the indicators. Here, a default value of half the record length is used (Dakos et al., 2008), but sensitivity analyses were performed where the length of the sliding window was varied from $25 \%$ of the record length up to $75 \%$ using increments of 20 points. A longer window length leads to more gradual changes in the indicators for the same dataset (Livina et al., 2012).

\subsection{Indicator trends}

Here, we consider upward trends in both ACF and DFA indicators as sufficient to indicate critical slowing down, regardless of the trend in variance. We use our sensitivity analyses to assess the robustness and strength of the trends in all three indicators. Indicator trends are quantified using the nonparametric Kendall $\tau$ rank correlation coefficient (Kendall, 1948). This measures, in the range -1 to +1 , the strength of the tendency of an indicator to increase (positive values) or decrease (negative values) with time, against the null hypothesis of randomness for a sequence of measurements against time (value approximately zero). We focus on trends in the indicators, because their absolute values are affected by the ratio between the time scale of the dynamics and the frequency of measurements. We plot each indicator value at the end of the sliding window from which it was calculated, to mimic the situation of not being able to access data from the future. However, if one were trying to estimate when critical behaviour will be reached in the future (indicators tending 


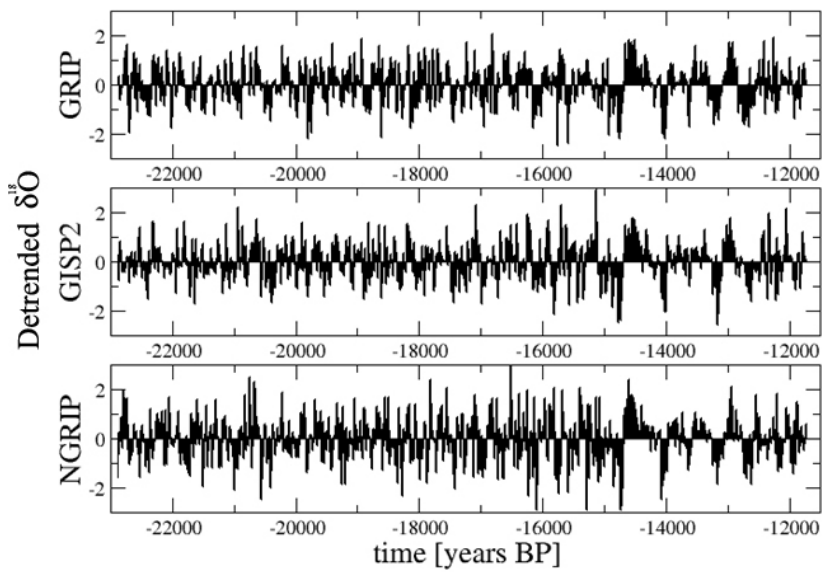

Fig. 2. Slowing down through the last deglaciation is visible clearly in detrended Greenland ice core $\delta^{18} \mathrm{O}$ paleo-temperature proxy data: (a) GRIP, (b) GISP2, (c) NGRIP. Example residuals after detrending $\delta^{18} \mathrm{O}$ records $22.88-11.74 \mathrm{ka}(n=558)$, through the Last Glacial Maximum to the end of the Younger Dryas, using a filtering bandwidth of 25 , showing pronounced slowing down, especially after the Bølling warming $(\sim 14.7 \mathrm{ka})$.

to 1), results should instead be plotted in the middle of the sliding window, and any trend extrapolated forward (with an appropriate error range).

\section{Results}

Simply detrending the $\delta^{18} \mathrm{O}$ data from any of the three ice cores over 22.9-11.7 ka and examining the residuals (Fig. 2), one can see clearly that over time, Greenland climate becomes prone to larger and longer fluctuations. In other words, the climate system becomes more sluggish in response to perturbations as it proceeds through the deglaciation. The slowing down is particularly pronounced during the BøllingAllerød warm period $\sim 14.7-12.9 \mathrm{ka}$, with some signs of a return to faster fluctuations during the Younger Dryas $\sim 12.9-11.7 \mathrm{ka}$. In the following sections we examine this signal in more detail.

\subsection{The deglaciation as a whole}

Analysing the $\delta^{18} \mathrm{O}$ data over $22.9-11.7 \mathrm{ka}$, the ACFindicator (AR(1) coefficient) and standard deviation rise together and roughly in proportion in the GRIP $\delta^{18} \mathrm{O}$ data (Fig. 3a) and in the GISP2 $\delta^{18} \mathrm{O}$ data (Fig. 3b), as expected from the fluctuation-dissipation theorem (Ditlevsen and Johnsen, 2010). There is some decoupling between the rises in the ACF-indicator and standard deviation in the NGRIP data (Fig. 3c), in particular, a downward trend in the variance after the Bølling warming, whilst the $\mathrm{ACF}$-indicator continues to rise. In GRIP, NGRIP and GISP $2 \delta^{18} \mathrm{O}$ data, for both the ACF and DFA indicators of slowing down, and the variance, positive trends are robust across a wide range of window lengths and filtering bandwidths used in the analysis (Fig. 3, colour contour plot insets).

Analysis of the $\log _{\mathrm{e}}\left[\mathrm{Ca}^{++}\right]$data from the three ice cores over 22.9-11.7 ka also shows positive trends in the ACF and DFA indicators of slowing down, and the variance (Fig. 4). These positive trends are even more robust to varying the window lengths and filtering bandwidths used in the analysis (Fig. 4, colour contour plot insets). Even if one considers raw $\left[\mathrm{Ca}^{++}\right]$data, there remain robust positive trends in ACF and DFA indicators of slowing down, but there are ambiguous trends in variance because $\left[\mathrm{Ca}^{++}\right]$is much less variable in the warm Bølling-Allerød interval, which is toward the end of the time series (results not shown).

Looking across all the results for both proxies (Figs. 3 and 4), increases in the indicators are typically concentrated toward the end of the time series, associated with the BøllingAllerød in particular. Furthermore, upward jumps in the indicators are associated with the Bølling warming, suggesting inadequate detrending of this abrupt transition influences the results. The detrending is improved by picking a shorter filtering bandwidth, e.g. 5 points, and the sensitivity analysis (colour contour plots in Figs. 3 and 4) shows that this can eliminate the positive trends in e.g. the ACF-indicator in GRIP and NGIP $\delta^{18} \mathrm{O}$, but not in GISP2 $\delta^{18} \mathrm{O}$ or any of the $\log _{\mathrm{e}}\left[\mathrm{Ca}^{++}\right]$datasets. The drawback of such a short filtering bandwidth is that it also eliminates low-frequency fluctuations during the Bølling-Allerød that are clearly visible in the original data and indicative of a slowing down in climate dynamics.

\subsection{The run-up to the Bølling warming}

This question of whether or not there is any slowing down in climate dynamics prior to the Bølling warming (Dakos et al., 2008; Ditlevsen and Johnsen, 2010) can be roughly answered by looking at the example indicators in the run-up to $\sim 14.7 \mathrm{ka}$ in Figs. 3 and 4 . This interval $22.9-14.7 \mathrm{ka}$ is analysed in more detail in Figs. 5 and 6.

In the run-up to the $\mathrm{B} \emptyset$ lling warming in GRIP $\delta^{18} \mathrm{O}$ data, the ACF indicator shows consistent speeding up, whilst the DFA indicator shows ambiguous trends (Fig. 5a). In GISP2 $\delta^{18} \mathrm{O}$ data (Fig. 5b), the ACF indicator generally shows slowing down, consistent with previously reported results (Dakos et al., 2008) (which are from a shorter interval of GISP $2 \delta^{18} \mathrm{O}$ data on a different time scale), but the DFA indicator shows consistent speeding up. In NGRIP $\delta^{18} \mathrm{O}$ data (Fig. 5c), the DFA indicator shows consistent speeding up, whilst the ACF indicator gives ambiguous trends, consistent with previous results (Ditlevsen and Johnsen, 2010). All three $\delta^{18}$ O records show robustly rising variance (Fig. $5 \mathrm{a}-\mathrm{c}$ ), whereas previous analyses of NGRIP $\delta^{18} \mathrm{O}$ suggested no trend in variance (Ditlevsen and Johnsen, 2010).

Analysis of the $\log _{\mathrm{e}}\left[\mathrm{Ca}^{++}\right]$data from the three ice cores over 22.9-14.7 ka also shows mixed results for the ACF and DFA indicators (Fig. 6), with the example indicators showing 
(a)
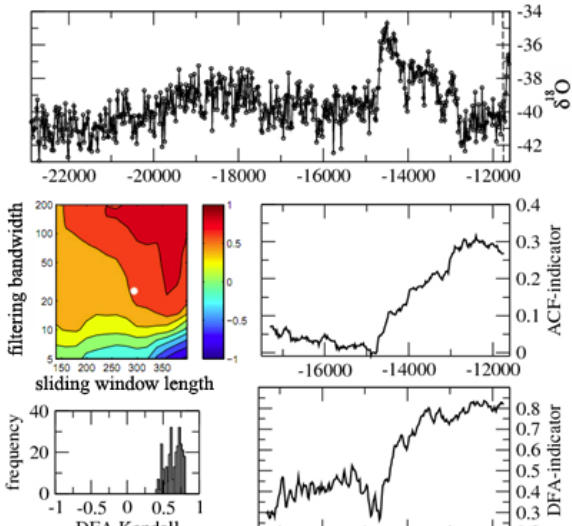

DFA Kendal
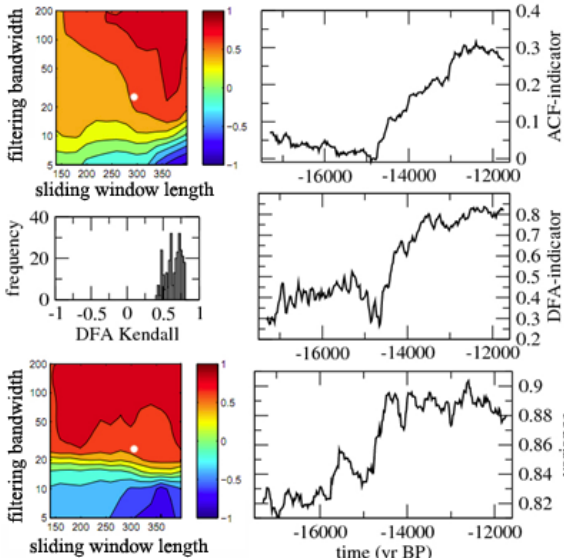

(b)

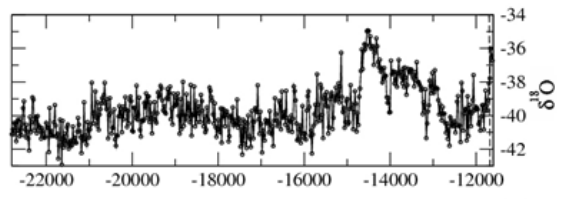

(c)

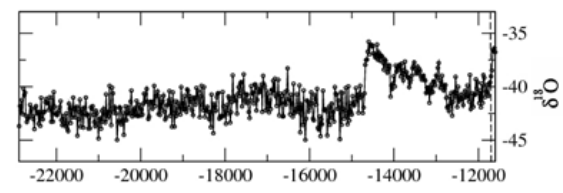

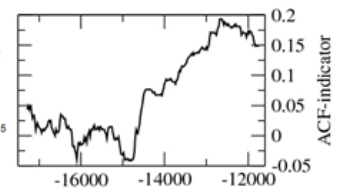
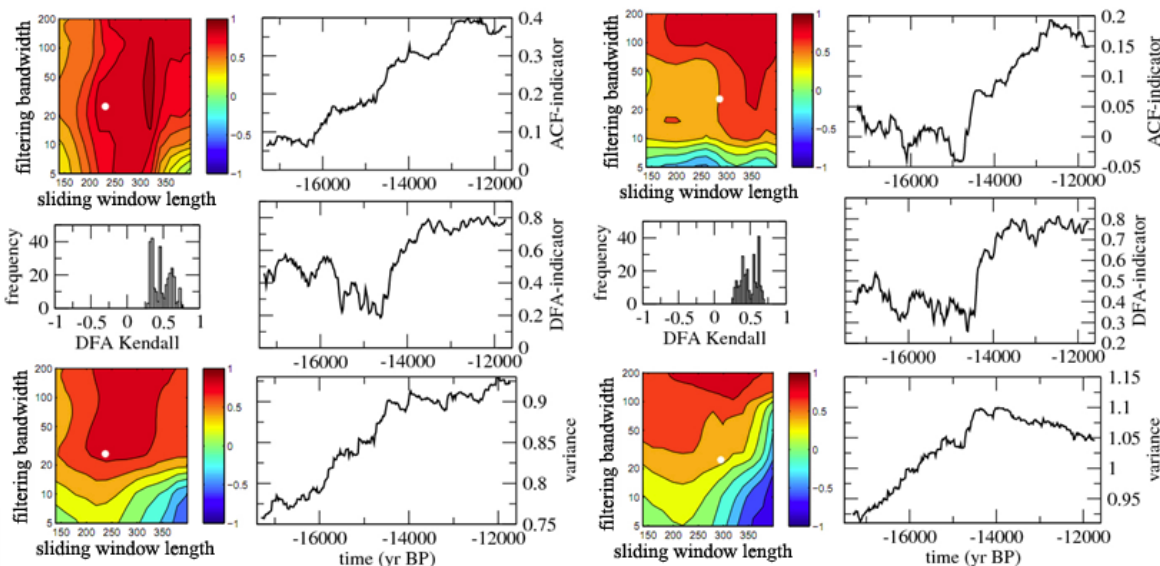

Fig. 3. Indicators of slowing down and changing variance in Greenland ice-core $\delta^{18} \mathrm{O}$ paleo-temperature proxy records through the last deglaciation: (a) GRIP (b) GISP2 (c) NGRIP. In each case, (Top panel) time series of $\delta^{18} \mathrm{O}$ data, where analysis spans $22.88-11.74 \mathrm{ka}$ $(n=558)$, through the Last Glacial Maximum, the Bølling-Allerød, and stopping at the vertical dashed line before the exit from the Younger Dryas. (Left panels) Sensitivity analysis showing values of the Kendall trend statistic for the indicators: (top) ACF, (middle) DFA, (bottom) variance, when varying the sliding window length and (for ACF and variance) the filtering bandwidth used in de-trending. White dots in the contour plots indicate the values of window length and filtering bandwidth used for the example indicators. (Right panels) Example indicators calculated after de-trending, using sliding window length of half the series and (for ACF and variance) a filtering bandwidth of 25: (top) ACF, (middle) DFA, (bottom) variance.

(a)
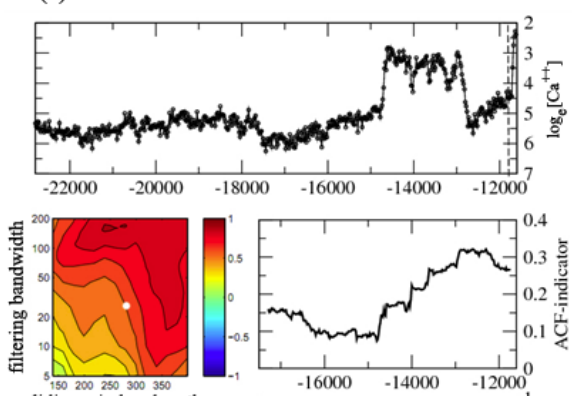

$150200250,300,350$
sliding window length
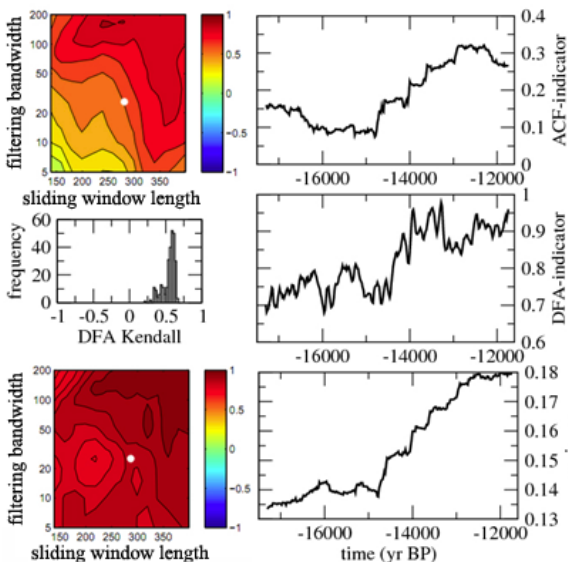

(b)
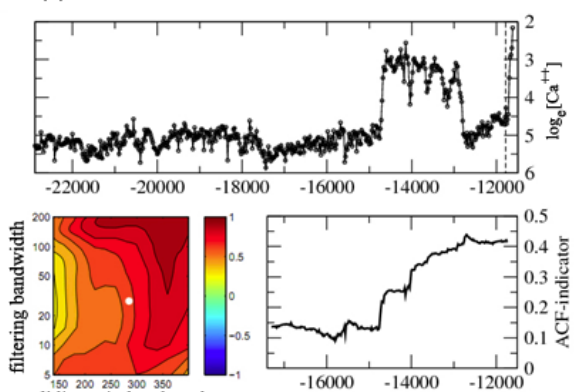

sliding window length
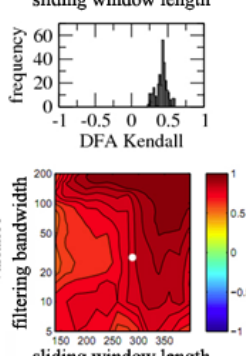
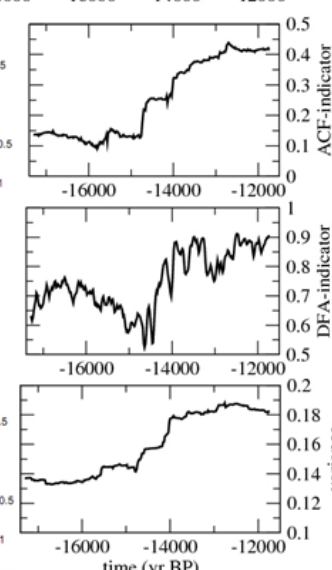

(c)
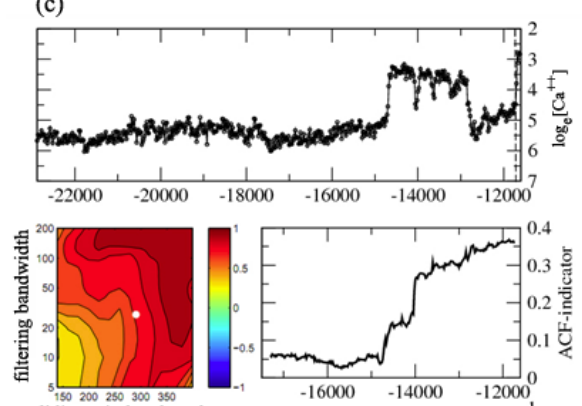

sliding window length
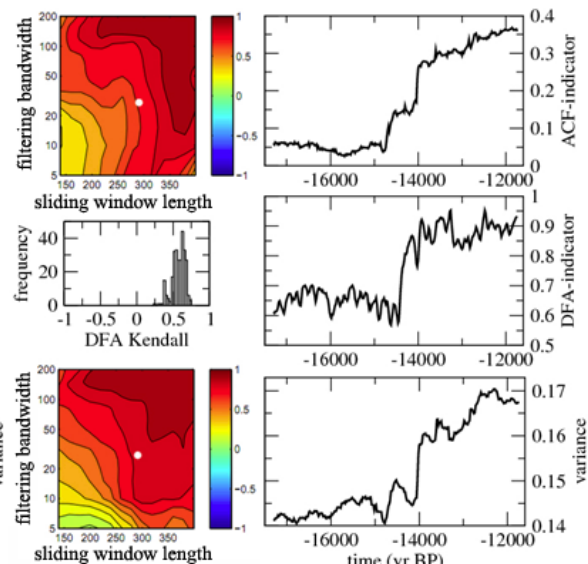

Fig. 4. Indicators of slowing down and changing variance in Greenland ice-core $\log _{\mathrm{e}}\left[\mathrm{Ca}^{++}\right]$records through the last deglaciation: (a) GRIP (b) GISP2 (c) NGRIP. Panel descriptions are as in Fig. 3. 
a general increase up to $\sim 17 \mathrm{ka}$ (the time of Heinrich event $1)$, but often a decline after that. Variance is also generally increasing when considering the data up to $\sim 17 \mathrm{ka}$ but declines after that, leading to some ambiguity in the indicators.

Looking across all the results for both proxies (Figs. 5 and 6 ), there is no robust, widespread slowing down prior to the $\mathrm{B} \varnothing$ lling warming, but there is a robust increase in $\delta^{18} \mathrm{O}$ variability (Fig. 5), and $\log _{\mathrm{e}}\left[\mathrm{Ca}^{++}\right]$variability also increases up to $\sim 17$ ka (Fig. 6).

\subsection{Spliced records of stadial climate dynamics}

According to current thinking and following our conceptual model (Fig. 1), the Bølling-Allerød represents a different inter-stadial climate state to the cold stadial state that both preceded it and followed it. If this interpretation is correct, then switching between one climate state and another is likely to involve a shift in dynamics that influences the indicators. Hence, to test the hypothesis that the cold, stadial climate state approaches a bifurcation on going through the deglaciation, we spliced the Younger Dryas onto what preceded the Bølling-Allerød. Analysis of the resulting composite stadial climate datasets shows mixed results (Figs. 7 and 8), which are not radically different to those for the runup to the Bølling warming (Figs. 5 and 6). In other words, adding on the Younger Dryas does not qualitatively alter the indicator trends and their sensitivity analysis.

Across the three $\delta^{18} \mathrm{O}$ datasets (Fig. 7), there is a robust overall rise in variance of the stadial climate state, although at NGRIP (Fig. 7c) there are signs of the variance dropping in the Younger Dryas. In GISP2 $\delta^{18} \mathrm{O}$ data (Fig. 7b), an upward trend in the ACF-indicator is strengthened by including the Younger Dryas, and the example DFA-indicator also starts to rise in the Younger Dryas. Whilst these GISP $2 \delta^{18} \mathrm{O}$ results appear consistent with critical slowing down, they are not reflected in the neighbouring GRIP $\delta^{18} \mathrm{O}$ or in NGRIP $\delta^{18} \mathrm{O}$, where the indicators are generally declining (Fig. 7a, c), with the exception of the DFA-indicator at GRIP.

The $\log _{\mathrm{e}}\left[\mathrm{Ca}^{++}\right]$results are even more varied (Fig. 8). The ACF-indicators all decline overall with no sign that including the Younger Dryas starts to reverse the trend. The DFAindicator rises at GRIP and NGRIP but declines at GISP2. Variance rises strongly at GRIP but less so at GISP2 and declines at NGRIP.

\subsection{The Bølling-Allerød and Younger Dryas at annual resolution}

When we analyse the Bølling-Allerød and Younger Dryas intervals separately at high resolution, using GRIP $\log _{e}(\mathrm{Ca})$ data (Fig. 9), the results carry the caveat that lag-1 autocorrelation (the ACF-indicator) shows different behaviour in annual data, apparently sampling fast decay modes that are not pertinent to bifurcation detection (Lenton et al., 2012). We have more confidence in the DFA-indicator, which shows comparable behaviour in annual and 20-yr resolution data. It shows no clear trend during the Bølling-Allerød suggesting unchanging stability properties (Fig. 9a). This is consistent with the onset of the Younger Dryas being caused by a perturbation. During the Younger Dryas there is some weak upward trend in the DFA indicator, but it is sensitive to the window length chosen (Fig. 9b). The strongest signal is a robust decline in variance within both the Bølling-Allerød and the Younger Dryas. In other words, inter-annual climate variability as recorded by $\log _{\mathrm{e}}(\mathrm{Ca})$ declines during the BøllingAllerød and, after rising with the transition into the Younger Dryas, declines again during the Younger Dryas itself. The declining inter-annual variability in the Younger Dryas is at odds with the rising variance at $20-y r$ resolution (Fig. 8a), which may indicate a shift in power from high to low frequencies (spectral reddening) that would be consistent with critical slowing down.

\section{Discussion}

We hypothesised that there was an approach to bifurcation during the last deglaciation in which the cold stadial climate state lost its stability. Several other dynamical systems models also suggest that the cessation of Dansgaard-Oeschger events on going from the last ice age to the Holocene involved an underlying bifurcation in climate dynamics (Timmermann et al., 2003; Colin de Verdiere, 2006; Crucifix, 2012). For example, Timmermann et al. (2003) (their Fig. 10) propose a model of a transition from an oscillating AMOC to a convective regime, which is a reversal through a Hopf bifurcation (from cyclic to fixed point attractor), in which case the signal of critical slowing down would be expected (Thompson and Sieber, 2011). Other models suggest a homoclinic bifurcation or an infinite period bifurcation (Colin de Verdiere, 2006). In the case of a homoclinic connection where a cycle connects to a saddle, then this should be characterised by the period of the cycle tending to infinity, but this is not particularly helpful, because if the behaviour is cyclic, there is only one instance of the cycle during the deglaciation, so there is no way to say if the cycle is getting longer. Although these various models suggest a climate bifurcation during the last deglaciation, the results we have obtained do not provide convincing support for the bifurcation hypothesis.

Interestingly in the model of Timmermann et al. (2003), entry into a Heinrich event, involving catastrophic iceberg discharge into the North Atlantic, is through a saddle-node (fold) bifurcation, which should show a slowing down signal. In the run-up to Heinrich event $\mathrm{H} 1 \sim 17 \mathrm{ka}$, the $\log _{\mathrm{e}}\left[\mathrm{Ca}^{++}\right]$ records all show an increase in variability and predominantly an increase in the ACF and DFA indicators of slowing down. The $\delta^{18} \mathrm{O}$ records also show increasing variability, but not a slowing down signal. 
(a)
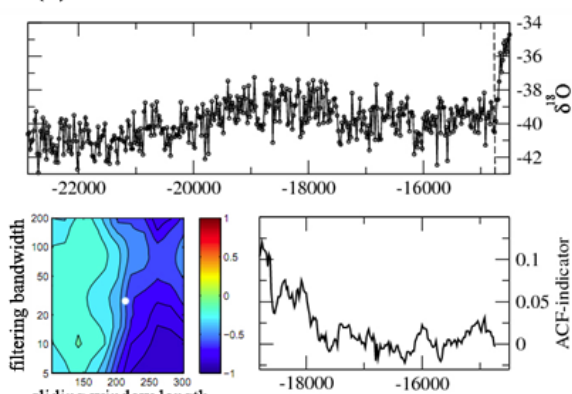

sliding window length
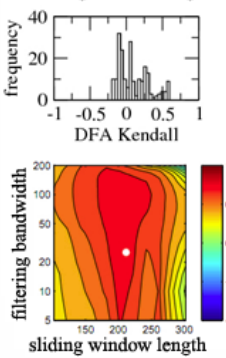

(b)
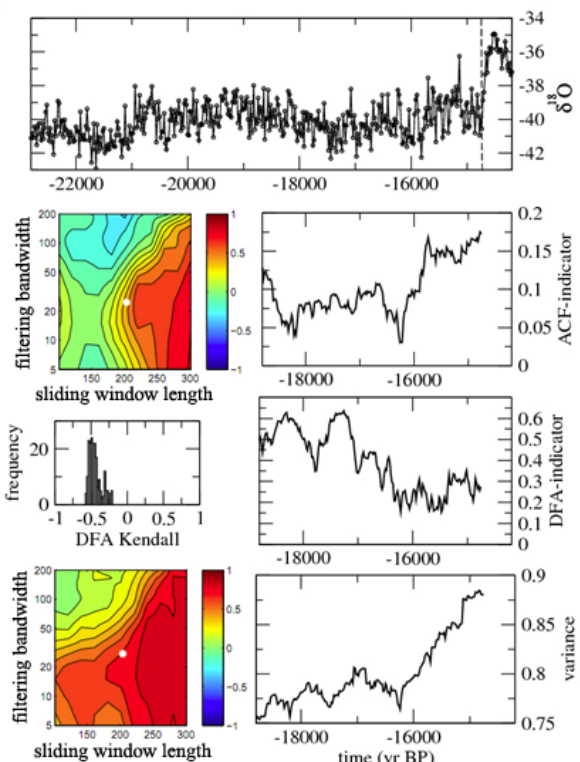

(c)
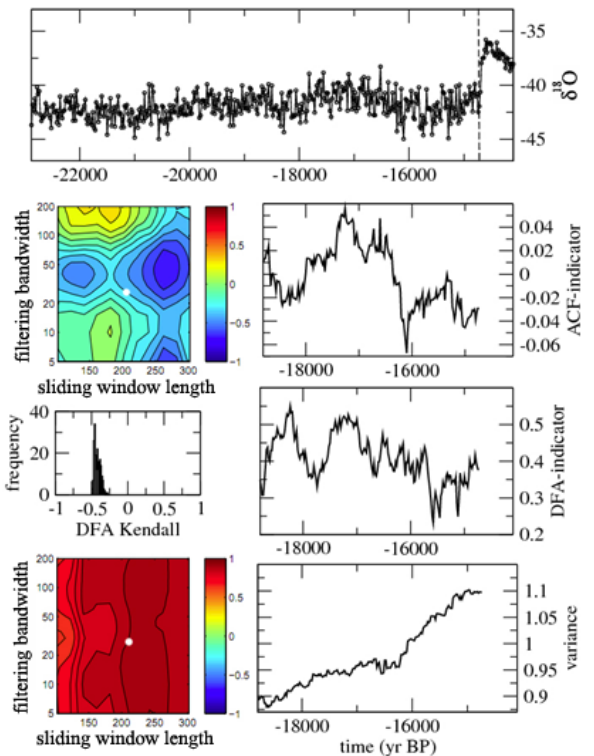

Fig. 5. Indicators of slowing down and changing variance in Greenland ice-core $\delta^{18} \mathrm{O}$ paleo-temperature proxy records during the interval after DO event 2 to the Bølling warming (DO event 1): (a) GRIP (b) GISP2 (c) NGRIP. Here the analysis spans 22.88-14.74 ka $(n=408$ ), stopping at the vertical dashed line before the Bølling warming. Otherwise panel descriptions are as in Fig. 3.

(a)
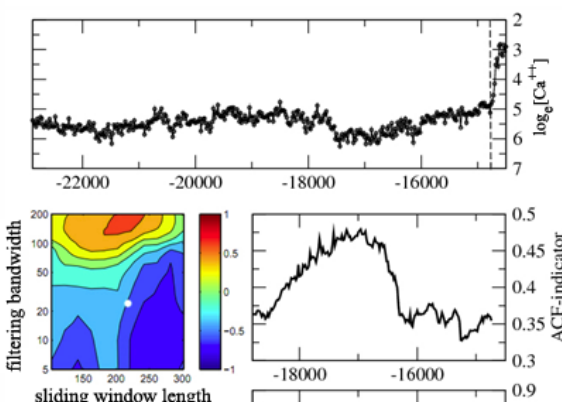

sliding window length

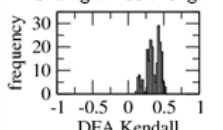

DFA Kendall
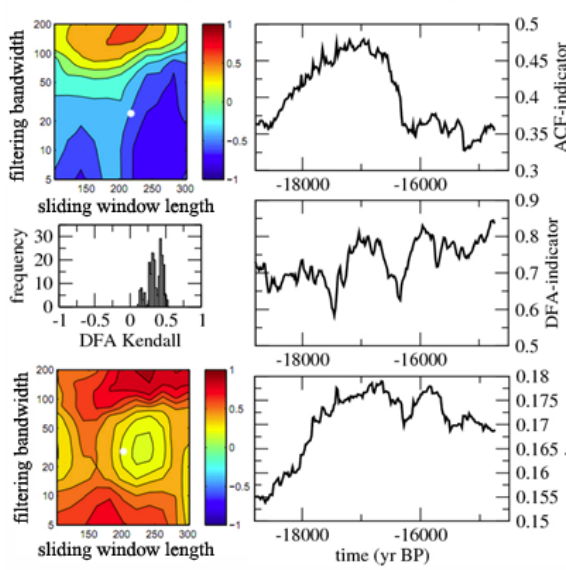

(b)
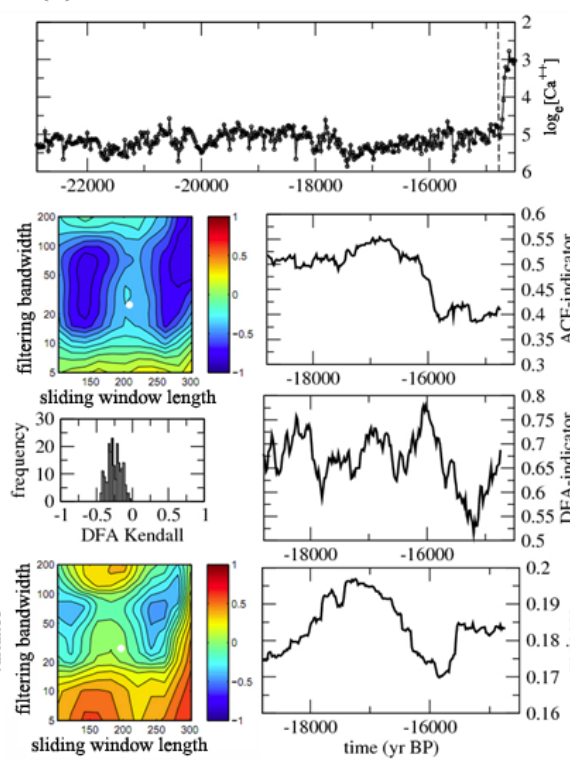

sliding window length

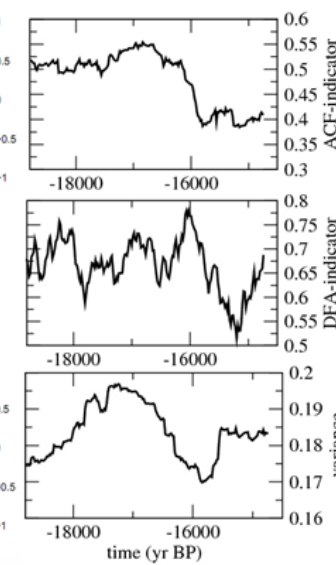

(c)
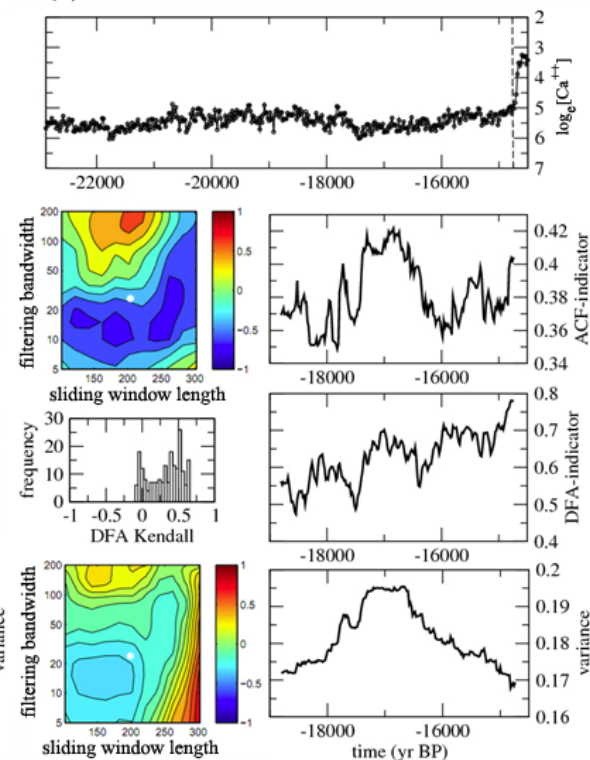

Fig. 6. Indicators of slowing down and changing variance in Greenland ice-core $\log _{\mathrm{e}}\left[\mathrm{Ca}^{++}\right]$records during the interval after DO event 2 to the Bølling warming (DO event 1): (a) GRIP (b) GISP2 (c) NGRIP. Here the analysis spans 22.88-14.74 ka $(n=408)$, stopping at the vertical dashed line before the Bølling warming. Otherwise panel descriptions are as in Fig. 3. 
Previously reported results showing critical slowing down prior to the Bølling warming in the GISP 2 core $\delta^{18} \mathrm{O}$ record (Dakos et al., 2008) are not supported by an alternative DFA indicator of critical slowing down. They are neither found in the GISP2 $\log _{\mathrm{e}}\left[\mathrm{Ca}^{++}\right]$record with either ACF or DFA indicators, nor in the neighbouring GRIP core $\delta^{18} \mathrm{O}$ record or in the more distant NGRIP core $\delta^{18} \mathrm{O}$ record. There is therefore no widespread, robust slowing down tendency prior to the Bølling warming, and no evidence that this abrupt climate change was caused by a bifurcation (in which the cold, dry climate state would have to have lost stability, as hinted at in earlier work (Crucifix and Berger, 2002)). This interpretation is consistent with the return to cold, dry conditions in the Younger Dryas, which suggests an alternative cold climate state remained stable during the early part of the deglaciation, even though it was not being sampled during the BøllingAllerød.

The abrupt Bølling warming event appears to have been caused by a stochastic fluctuation (Ditlevsen and Johnsen, 2010). This fluctuation could have taken the form of a rapid, large perturbation. The Atlantic meridional overturning circulation (AMOC) had been shut down (McManus et al., 2004) from $\sim 17 \mathrm{ka}$, in response to Heinrich event H1, and it resumed abruptly at the Bølling warming (McManus et al., 2004). The triggering fluctuation may have been a sudden cessation of meltwater discharge into the North Atlantic (Clark et al., 2001; Liu et al., 2009), or meltwater pulse 1A originating from Antarctica (Weaver et al., 2000). However, models require much larger freshwater perturbations to affect a transition than data constraints allow (Valdes, 2011), and they generally exhibit much lower internal variability than the real glacial climate. An alternative interpretation, following Ditlevsen and Johnsen (2010), is that the level of glacial climate variability was such that it could (very occasionally) tip the system into an alternative warm state. This interpretation is helped by the observation that the strongest signal prior to the $\mathrm{B} \emptyset$ lling warming is an increase in paleotemperature variability as recorded by $\delta^{18} \mathrm{O}$ (Fig. 3). We conclude that a switch between co-existing cold and warm climate states occurred at the Bølling warming.

The noise-induced switch at the Bølling warming may have been preceded by a bifurcation that re-created a stable, warm climate state, which had lost its stability during the Last Glacial Maximum (Livina et al., 2010). However, the methods applied here would not be able to detect that, as the climate system was only sampling the cold climate state $22.9-14.7 \mathrm{ka}$, and they focus on deducing changes to its stability properties.

The Bølling warming marked a distinct destabilisation of the climate system. On going through the transition, autocorrelation and variance generally increase in the six ice core records (Figs. 3 and 4). This is not purely a consequence of inadequate detrending of the abrupt transition (although that contributes). There is also a clear shift to lower frequency fluctuations. This suggests the warm climate state that had been entered was less stable than the preceding cold state of the Last Glacial Maximum. The multi-centennial climate fluctuations during the Bølling-Allerød period can be clearly seen in the $\delta^{18} \mathrm{O}$ and $\log _{\mathrm{e}}\left[\mathrm{Ca}^{++}\right]$data (Figs. 3 and 4). Their time scale is consistent with an internal low-frequency mode of variability of the AMOC found in models (Mikolajewicz and Maier-Reimer, 1990; Park and Latif, 2008). Furthermore, decreases in AMOC strength centred on $\sim 14.1 \mathrm{ka}$, $\sim 13.8 \mathrm{ka}$ and $\sim 13.3 \mathrm{ka}$ have been detected in proxy data (Hughen et al., 2000; Obbink et al., 2010), and linked to temperature minima in Greenland (Obbink et al., 2010), North America and Europe (Yu and Eicher, 2001) (known as the intra-Bølling cold period, Older Dryas, and intra-Allerød cold period, respectively). Fluctuations in the eastward routing of freshwater from the Laurentide ice sheet occurred at these times (Clark et al., 2001; Obbink et al., 2010) and may have contributed to AMOC weakening (Obbink et al., 2010), but could equally be viewed as the result of fluctuations in AMOC strength affecting temperatures over the ice sheet (Clark et al., 2001). Thus, we hypothesise that the Bølling warming excited oscillations in the AMOC, coupled to the Laurentide ice sheet.

The overall shift to a less stable, warm climate state may have facilitated further abrupt changes. We find no overall slowing down trend during the Bølling-Allerød period itself. This is consistent with the onset of the Younger Dryas $\sim 12.9$ ka being caused by a perturbation rather than a bifurcation. In our characterisation of the climate as a slow-fast system (Fig. 1), the warm Bølling-Allerød climate state increased freshwater input to the North Atlantic, thus contributing to its own demise. In reality, this could have been a sporadic affair, with deglacial meltwater accumulating and then being occasionally purged. This is consistent with the hypothesis that the onset of the Younger Dryas $\sim 12.9 \mathrm{ka}$, was caused by a catastrophic release of deglacial meltwater, probably involving the northward draining of Lake Agassiz into the Arctic Ocean (Murton et al., 2010). Alternative hypotheses for the trigger of the Younger Dryas include an extraterrestrial impact (Israde-Alcantara et al., 2012), which might by $(\operatorname{sim})$ chance have hit near enough to have triggered deglacial meltwater release.

With the onset of the Younger Dryas $\sim 12.9 \mathrm{ka}$, ventilation of the deep Atlantic may have temporarily ceased (McManus et al., 2004; Hughen et al., 2000). However, North Atlantic deep water formation soon resumed (Elmore and Wright, 2011). Overall, the Younger Dryas was characterised by a weak but not collapsed AMOC (McManus et al., 2004), somewhat analogous to its cold (stadial) mode of operation during the ice age. Thus, we interpret the transition into the Younger Dryas as a switch back into a co-existing cold climate state, triggered by a large perturbation. However, the onset of the Younger Dryas was not as abrupt as the Bølling warming or the end of the Younger Dryas (Steffensen et al., 2008). 
(a)
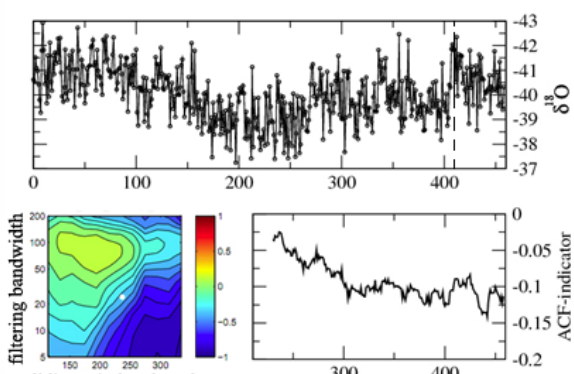

sliding window length

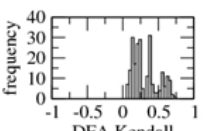

DFA Kendall
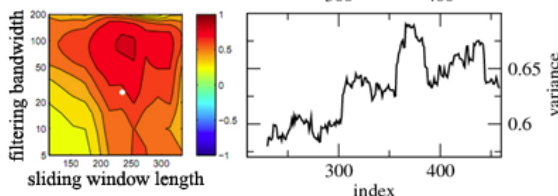

(b)
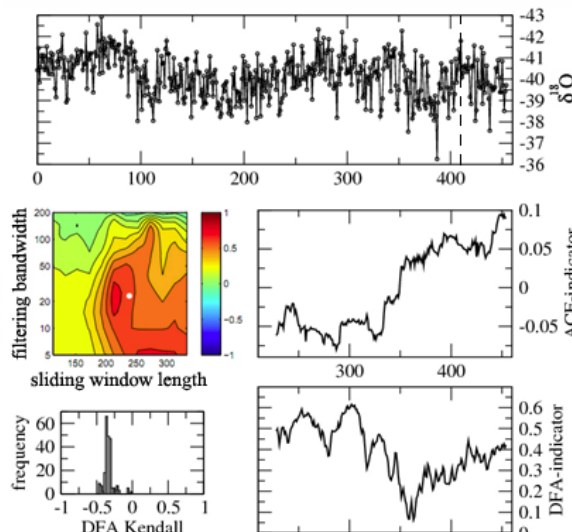

DFA Kendall

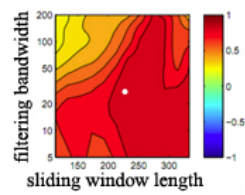

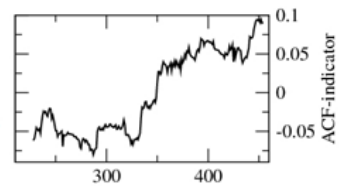
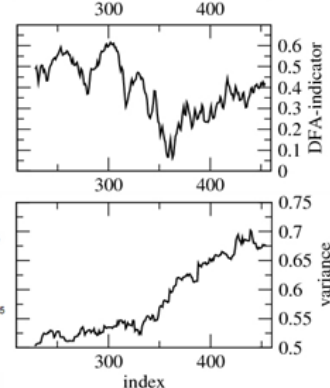

sliding window length (c)
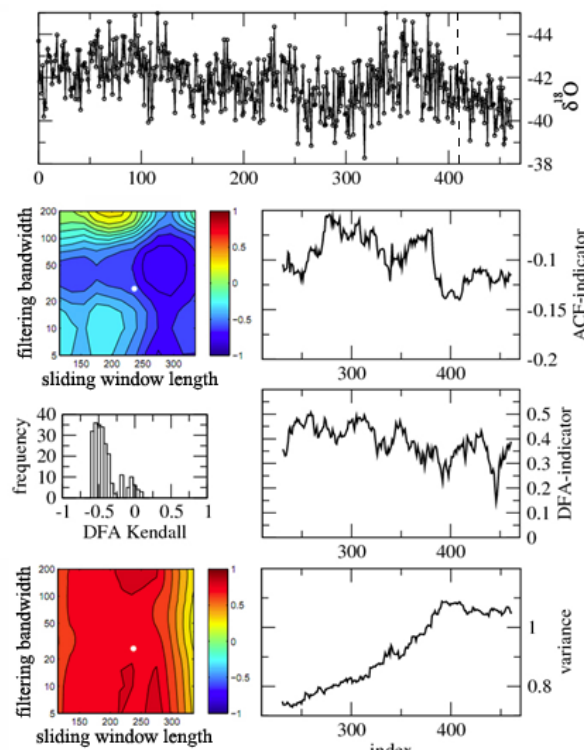

Fig. 7. Indicators of slowing down and changing variance of the stadial climate state, joining Greenland ice-core $\delta^{18} \mathrm{O}$ paleo-temperature proxy records of the run-up to the Bølling warming to the Younger Dryas: (a) GRIP (b) GISP2 (c) NGRIP. Here the data 22.88-14.76 ka are spliced to $12.68-11.74 \mathrm{ka}(n=455)$ at the point indicated by the vertical dashed line, and the resulting time series is just given an index value (point number). Otherwise panel descriptions are as in Fig. 3.

(a)
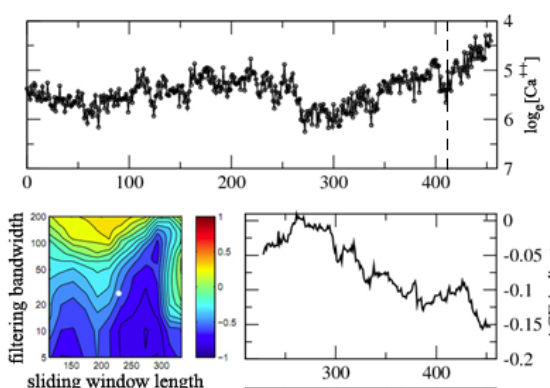

sliding window length

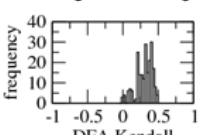

DFA Kendall

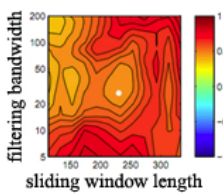

(b)
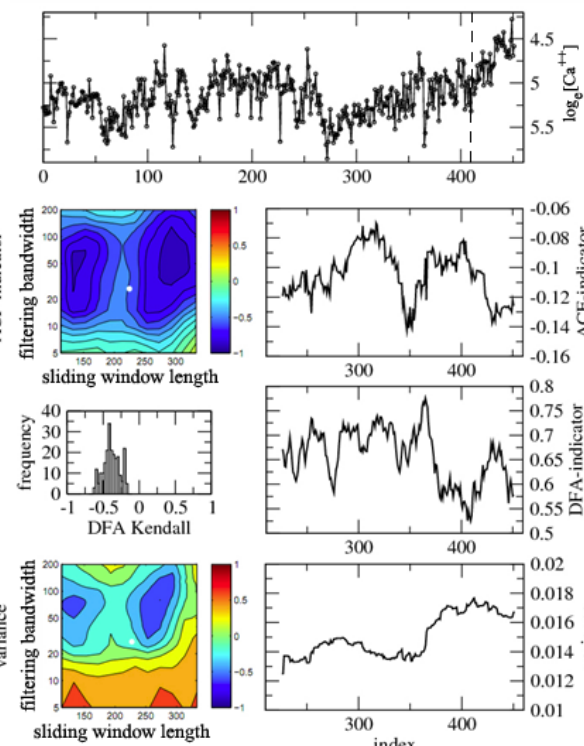
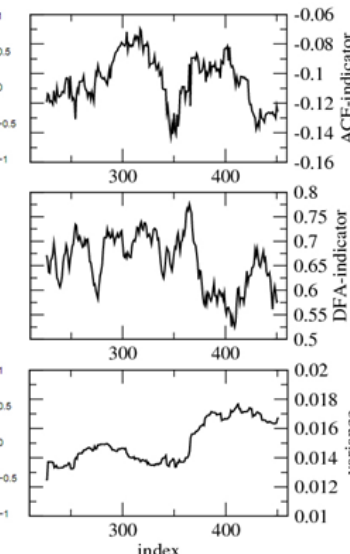

(c)
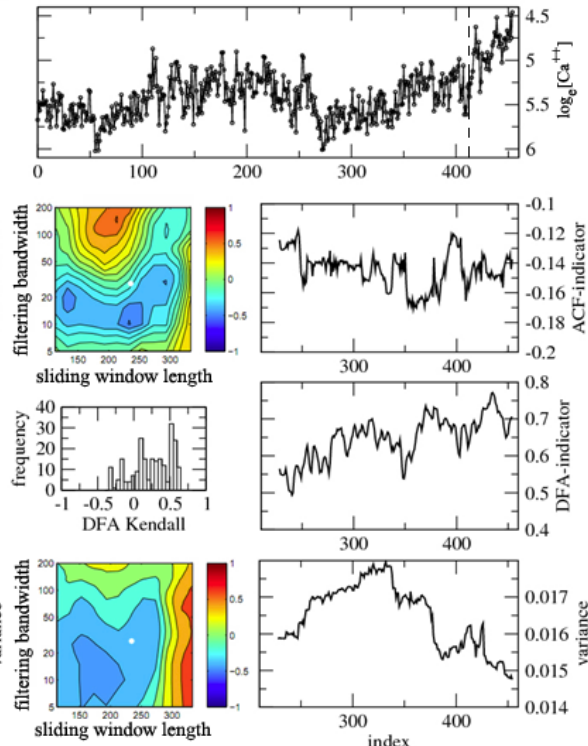

Fig. 8. Indicators of slowing down and changing variance of the stadial climate state, joining Greenland ice-core $\log _{\mathrm{e}}\left[\mathrm{Ca}{ }^{++}\right] \mathrm{records}$ of the run-up to the Bølling warming to the Younger Dryas at the point indicated by the vertical dashed line: (a) GRIP (b) GISP2 (c) NGRIP. Panel descriptions are as in Fig. 3. 
(a)
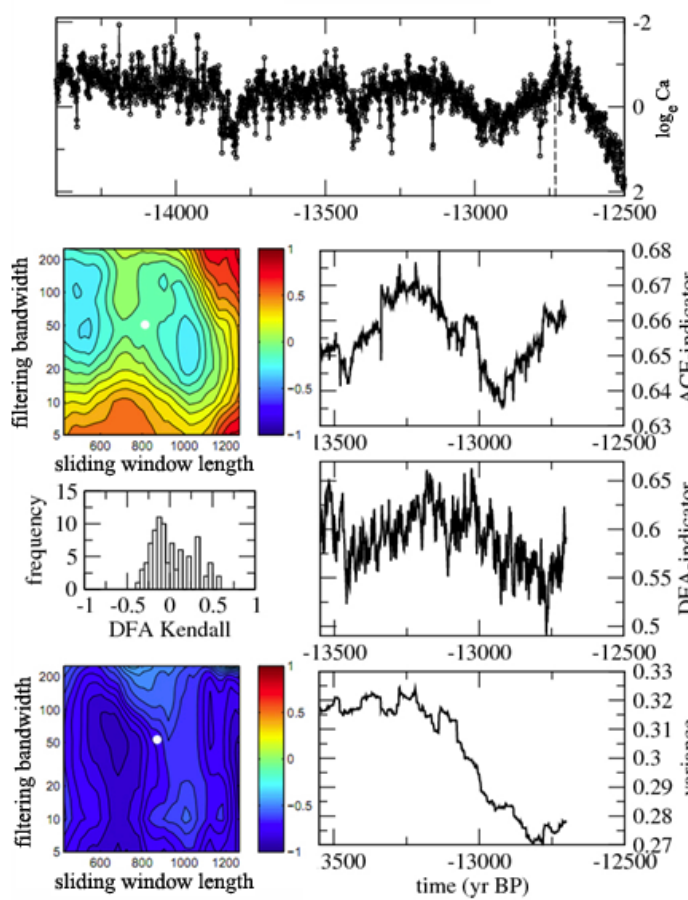
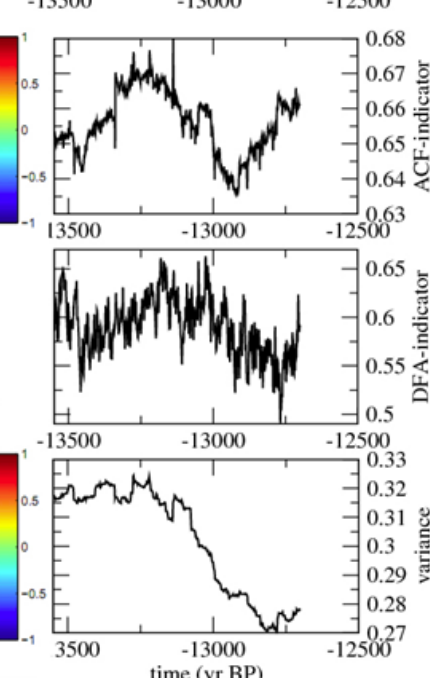

(b)
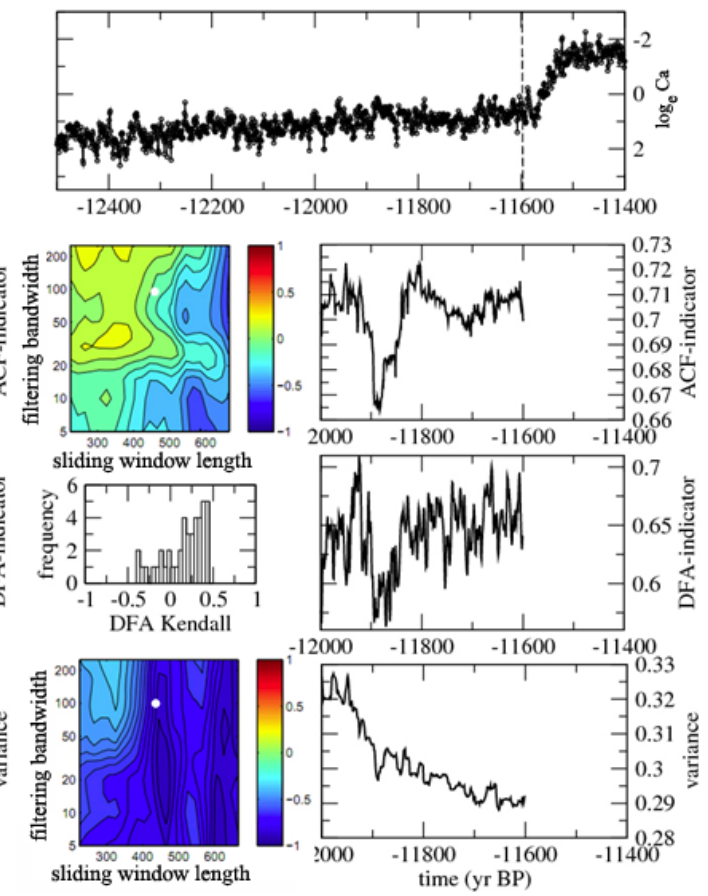

Fig. 9. Indicators of slowing down and changing variance in annual resolution GRIP ice core $\log _{e} C a$ records of (a) the Bølling-Allerød and (b) the Younger Dryas. Panel descriptions as in Fig. 3.

The Younger Dryas has previously been found to exhibit slowing down in a high-resolution productivity proxy from a sediment core in the tropical Atlantic (Dakos et al., 2008) (Cariaco basin). However, our results from Greenland ice cores do not provide convincing support for the hypothesis that the climate approached a bifurcation at the end of the Younger Dryas. The stadial climate state exhibits no consistent slowing down signal in either $\delta^{18} \mathrm{O}$ or $\log _{\mathrm{e}}\left[\mathrm{Ca}^{++}\right]$ data. Thus, without an obvious proximate trigger perturbation, the cause of the abrupt warming at the end of the Younger Dryas $\sim 11.7 \mathrm{ka}$ remains a puzzle. The transition itself lasted $\sim 60 \mathrm{yr}$, an order of magnitude slower than the Bølling warming (Steffensen et al., 2008), suggesting somewhat different underlying dynamics.

Our failure to find support for the bifurcation hypothesis does not necessarily falsify it. A single realisation of a system approaching a bifurcation may, by chance, not show the expected indicators of critical slowing down (Kuehn, 2011). Ideally, one should work with an ensemble of realisations of a system to build up better statistics for hypothesis testing. Unfortunately, there is only one realisation of deglaciation for which sufficiently high-resolution climate data are available. However, an alternative study examining whether the triggering of individual Dansgaard-Oeschger events involves any tendency toward bifurcation could make use of the ensemble of over 20 such events in Greenland ice core records.

\section{Conclusions}

We find signals consistent with critical slowing down through the last deglaciation, in two proxies from three different Greenland ice cores. However, these signals are partly a result of inadequate detrending of abrupt transitions and partly reflect the fact that the warm inter-stadial climate state sampled during the Bølling-Allerød period exhibited low frequency variability that was not present in the cold stadial climate state that preceded it or the Younger Dryas that followed it. The Bølling warming event marked a distinct destabilisation of the climate system, followed by oscillatory dynamics. However, the climate system remained bistable (with warm and cold states co-existing under a range of boundary conditions). Based on existing results, we hypothesised that a bifurcation point was approached at the end of the Younger Dryas, in which the prevailing cold climate state, with weak Atlantic overturning circulation, lost its stability, and the climate tipped irreversibly into a warm interglacial state. However, we failed to find convincing evidence in support of this hypothesis. This also questions alternative dynamical system models that suggest the cessation of Dansgaard-Oeschger events involved a bifurcation. We are left with the null hypothesis that the abrupt entry into the Holocene, as recorded in Greenland, was triggered by internal climate variability and an alternative, cold climate state remained stable. This fails to explain why subsequent 
meltwater perturbations did not cause sustained cooling. Further work should establish a framework of statistical testing against a null hypothesis to try and advance understanding of the dynamics of past abrupt climate changes.

Acknowledgements. Ice core data are from the Centre for Ice and Climate, Niels Bohr Institute, University of Copenhagen, P. D. Ditlevsen provided the high-resolution Ca data and useful advice on comparing it to $\delta^{18} \mathrm{O}$. We thank M. Crucifix and T. Kleinen for their constructive critiques which considerably altered the paper. T. M. L. and V. N. L. thank the Isaac Newton Institute for Mathematical Sciences, Cambridge University, for hosting them in the "Mathematical and Statistical Approaches to Climate Modelling and Prediction" programme. T. M. L. and V. N. L. are supported by NERC through the project "Detecting and classifying bifurcations in the climate system" (NE/F005474/1). V. N. L. holds an AXA postdoctoral fellowship. V. D. and M. S. are supported by a Spinoza award from the Dutch Science Foundation (NWO) and a European Research Council (ERC) grant awarded to M. S.

Edited by: U. Mikolajewicz

\section{References}

Alley, R. B.: GISP2 Ice Core Temperature and Accumulation Data, NOAA/NGDC Paleoclimatology Program, Boulder, CO, 2004.

Alley, R. B., Marotzke, J., Nordhaus, W. D., Overpeck, J. T., Peteet, D. M., Pielke, R. A., Pierrehumbert, R. T., Rhines, P. B., Stocker, T. F., Talley, L. D., and Wallace, J. M.: Abrupt Climate Change, Science, 299, 2005-2010, 2003.

Bard, E., Hamelin, B., and Delanghe-Sabatier, D.: Deglacial Meltwater Pulse 1B and Younger Dryas Sea Levels Revisited with Boreholes at Tahiti, Science, 327, 1235-1237, doi:10.1126/science.1180557, 2010.

Carpenter, S. R. and Brock, W. A.: Rising variance: a leading indicator of ecological transition, Ecol. Lett., 9, 311-318, doi:10.1111/j.1461-0248.2005.00877.x, 2006.

Clark, P. U., Marshall, S. J., Clarke, G. K. C., Hostetler, S. W., Licciardi, J. M., and Teller, J. T.: Freshwater Forcing of Abrupt Climate Change During the Last Glaciation, Science, 293, 283-287, doi:10.1126/science.1062517, 2001.

Colin de Verdiere, A.: Bifurcation structure of thermohaline millennial oscillations, J. Climate, 19, 5777-5795, 2006.

Crucifix, M.: Oscillators and relaxation phenomena in Pleistocene climate theory, Philos. T. R. Soc. A, 370, 1140-1165, doi:10.1098/rsta.2011.0315, 2012.

Crucifix, M. and Berger, A.: Simulation of ocean-ice sheet interactions during the last deglaciation, Paleoceanography, 17, 1054, doi:10.1029/2001pa000702, 2002.

Dakos, V., Scheffer, M., van Nes, E. H., Brovkin, V., Petoukhov, V., and Held, H.: Slowing down as an early warning signal for abrupt climate change, Proc. Natl. Acad. Sci. USA, 105, 14308-14312, 2008.

Dakos, V., van Nes, E. H., D’Odorico, P., and Scheffer, M.: Robustness of variance and autocorrelation as indicators of critical slowing down, Ecology, 93, 264-271, doi:10.1890/11-0889.1, 2012.

Dansgaard, W., Johnsen, S. J., Clausen, H. B., Dahl-Jensen, D., Gundestrup, N. S., Hammer, C. U., Hvidberg, C. S., Steffensen,
J. P., Sveinbjornsdottir, A. E., Jouzel, J., and Bond, G.: Evidence for general instability of past climate from a 250-kyr ice-core record, Nature, 364, 218-220, 1993.

Ditlevsen, P. D. and Johnsen, S. J.: Tipping points: Early warning and wishful thinking, Geophys. Res. Lett., 37, L19703, doi:10.1029/2010GL044486, 2010.

Elmore, A. C. and Wright, J. D.: North Atlantic Deep Water and climate variability during the Younger Dryas cold period, Geology, 39, 107-110, doi:10.1130/g31376.1, 2011.

Ganopolski, A. and Rahmstorf, S.: Rapid changes of glacial climate simulated in a coupled climate model, Nature, 409, 153$158,2001$.

Held, H. and Kleinen, T.: Detection of climate system bifurcations by degenerate fingerprinting, Geophys. Res. Lett., 31, L23207, doi:10.1029/2004GL020972, 2004.

Hughen, K. A., Southon, J. R., Lehman, S. J., and Overpeck, J. T.: Synchronous Radiocarbon and Climate Shifts During the Last Deglaciation, Science, 290, 1951-1954, 2000.

Israde-Alcantara, I., Bischoff, J. L., Dominguez-Vazquez, G., Li, H.-C., DeCarli, P. S., Bunch, T. E., Wittke, J. H., Weaver, J. C., Firestone, R. B., West, A., Kennett, J. P., Mercer, C., Xie, S., Richman, E. K., Kinzie, C. R., and Wolbach, W. S.: Evidence from central Mexico supporting the Younger Dryas extraterrestrial impact hypothesis, Proc. Natl. Acad. Sci., 109, E738-E747, doi:10.1073/pnas.1110614109, 2012.

Kendall, M. G.: Rank Correlation Methods, Charles Griffin \& Company Limited, London, 1948.

Kuehn, C.: A mathematical framework for critical transitions: bifurcations, fast-slow systems and stochastic dynamics, Physica D: Nonlinear Phenomena, 2010, 1-20, 2011.

Lenton, T. M.: Early warning of climate tipping points, Nat. Clim. Change, 1, 201-209, doi:10.1038/nclimate1143, 2011.

Lenton, T. M., Held, H., Kriegler, E., Hall, J., Lucht, W., Rahmstorf, S., and Schellnhuber, H. J.: Tipping Elements in the Earth's Climate System, Proc. Natl. Acad. Sci. USA, 105, 1786-1793, doi:10.1073/pnas.0705414105, 2008.

Lenton, T. M., Livina, V. N., Dakos, V., van Nes, E. H., and Scheffer, M.: Early warning of climate tipping points from critical slowing down: comparing methods to improve robustness, Philos. T. R. Soc. A, 370, 1185-1204, doi:10.1098/rsta.2011.0304, 2012.

Liu, Z., Otto-Bliesner, B. L., He, F., Brady, E. C., Tomas, R., Clark, P. U., Carlson, A. E., Lynch-Stieglitz, J., Curry, W., Brook, E., Erickson, D., Jacob, R., Kutzbach, J., and Cheng, J.: Transient Simulation of Last Deglaciation with a New Mechanism for BøllingAllerød Warming, Science, 325, 310-314, 2009.

Livina, V. N. and Lenton, T. M.: A modified method for detecting incipient bifurcations in a dynamical system, Geophys. Res. Lett., 34, L03712, doi:10.1029/2006GL028672, 2007.

Livina, V. N., Kwasniok, F., and Lenton, T. M.: Potential analysis reveals changing number of climate states during the last $60 \mathrm{kyr}$, Clim. Past, 6, 77-82, doi:10.5194/cp-6-77-2010, 2010.

Livina, V. N., Ditlevsen, P. D., and Lenton, T. M.: An independent test of methods of detecting and anticipating bifurcations in time-series data, Physica A: Statistical Mechanics and its Applications, 391, 485-496, 2012.

McManus, J. F., Francois, R., Gherardi, J. M., Keigwin, L. D., and Brown-Leger, S.: Collapse and rapid resumption of Atlantic meridional circulation linked to deglacial climate changes, Nature, 428, 834-837, doi:10.1038/nature02494, 2004. 
Mikolajewicz, U. and Maier-Reimer, E.: Internal secular variability in an ocean general circulation model, Clim. Dynam., 4, 145156, 1990.

Murton, J. B., Bateman, M. D., Dallimore, S. R., Teller, J. T., and Yang, Z.: Identification of Younger Dryas outburst flood path from Lake Agassiz to the Arctic Ocean, Nature, 464, 740-743, doi:10.1038/nature08954, 2010.

NGRIP: High-resolution record of Northern Hemisphere climate extending into the last interglacial period, Nature, 431, 147-151, 2004.

Obbink, E. A., Carlson, A. E., and Klinkhammer, G. P.: Eastern North American freshwater discharge during the Bolling-Allerod warm periods, Geology, 38, 171-174, doi:10.1130/g30389.1, 2010.

Park, W. and Latif, M.: Multidecadal and multicentennial variability of the meridional overturning circulation, Geophys. Res. Lett., 35, L22703, doi:10.1029/2008g1035779, 2008.

Rasmussen, S. O., Seierstad, I. K., Andersen, K. K., Bigler, M., Dahl-Jensen, D., and Johnsen, S. J.: Synchronization of the NGRIP, GRIP, and GISP2 ice cores across MIS 2 and palaeoclimatic implications, Quaternary Sci. Rev., 27, 18-28, 2008.

Scheffer, M., Bacompte, J., Brock, W. A., Brovkin, V., Carpenter, S. R., Dakos, V., Held, H., van Nes, E. H., Rietkerk, M., and Sugihara, G.: Early warning signals for critical transitions, Nature, 461, 53-59, 2009.
Steffensen, J. P., Andersen, K. K., Bigler, M., Clausen, H. B., DahlJensen, D., Fischer, H., Goto-Azuma, K., Hansson, M., Johnsen, S. J., Jouzel, J., Masson-Delmotte, V., Popp, T., Rasmussen, S. O., Röthlisberger, R., Ruth, U., Stauffer, B., Siggaard-Andersen, M.-L., Sveinbjörnsdóttir, Á. E., Svensson, A., and White, J. W. C.: High-Resolution Greenland Ice Core Data Show Abrupt Climate Change Happens in Few Years, Science, 321, 680-684, 2008.

Thompson, J. M. T. and Sieber, J.: Predicting climate tipping as a noisy bifurcation: a review, Int. J. Bifurcat. Chaos, 21, 399-423, doi:10.1142/S0218127411028519, 2011.

Timmermann, A., Gildor, H., Schulz, M., and Tziperman, E.: Coherent Resonant Millennial-Scale Climate Oscillations Triggered by Massive Meltwater Pulses, J. Climate, 16, 2569-2585, 2003.

Valdes, P.: Built for stability, Nat. Geosci., 4, 414-416, 2011.

Weaver, A. J., Saenko, O. A., Clark, P. U., and Mitrovica, J. X.: Meltwater Pulse 1A from Antarctica as a Trigger of the BøllingAllerød Warm Interval, Science, 299, 1709-1713, 2000.

Wiesenfeld, K. and McNamara, B.: Small-signal amplification in bifurcating dynamical systems, Phys. Rev. A, 33, 629-642, 1986.

Wissel, C.: A universal law of the characteristic return time near thresholds, Oecologia, 65, 101-107, doi:10.1007/bf00384470, 1984.

Yu, Z. and Eicher, U.: Three amphi-Atlantic century-scale cold events during the Bølling-Allerød warm period, Géogr. Phys. Quatern., 55, 171-179, 2001. 